\title{
A Study to Develop and Evaluate the Effectiveness of a Mobile App: Samrudheart on Self-Care Management of a Patient with Heart Failure in Terms of Knowledge, Practice, and Adherence to Treatment among Heart Failure Patients in Safdarjung Hospital, New Delhi
}

\author{
Poonam $^{1}$, Madhumita Dey ${ }^{2}$, R. G Mathur ${ }^{3}$, Preety Gupta ${ }^{4}$ \\ 'Clinical Instructor, M.Sc. Nursing, Rajkumari Amrit Kaur College of Nursing, New Delhi. \\ ${ }^{2}$ Assistant Professor, R.N., R.M., M.N, Rajkumari Amrit Kaur College of Nursing, New Delhi. \\ ${ }^{3}$ Ex Faculty, B.Sc., M.Ed., Ph.D. Rajkumari Amrit Kaur College of Nursing, New Delhi. \\ ${ }^{4}$ Assistant Professor, V.M.M.C \& Safdarjung Hospital, New Delhi.
}

Corresponding Author: Poonam

\begin{abstract}
Topic: A study to develop and evaluate the effectiveness of mobile app: Samrudheart on self-care management of patient with heart failure in terms of knowledge, practice, and adherence to treatment among heart failure patients in Safdarjung Hospital, New Delhi.

Objectives: The objectives of the study were to develop and evaluate the effectiveness of mobile app: Samrudheart on self-care management of patient with heart failure, to assess and evaluate the knowledge, practice, and adherence to the treatment of heart failure patients, to find the relationship between knowledge, practice, and adherence to treatment after the administration of mobile app, on heart failure patients, to find the association between knowledge, practice, and adherence to treatment of heart failure patients after the administration of mobile app on selfcare management of heart failure with selected variables like age, sex, education status, family income, BMI, duration of illness, smoking, tobacco use, alcohol intake, lifestyle, diet, regular follow-up.

Methodology: The research approach was the quasi-experimental approach. The Research design was one group pre-test and post-test control group design. The research setting selected for the study was cardiology OPD of VMMC and Safdarjung Hospital, New Delhi. The sample was comprised of (60) Heart Failure patients attending cardiology OPD. The independent variable in the study was a mobile app: Samrudheart and reminder call for adherence to treatment on self-care management of a patient with heart failure and the dependent variable was knowledge, practice, and adherence to treatment on self-care management of heart failure. The tool used for data collection were demographic data of sample characteristics, health determinant data of sample characteristics, structured knowledge questionnaire, structured practice checklist, structured adherence to the treatment rating scale, and structured opinionnaire. The KR-20, inter-observer and Cronbach's alpha formula was used to assess the reliability of tools.

Results: Major findings of the study revealed that initially, the heart failure patients had poor knowledge, practice, and adherence to treatment on self-care management of heart failure. The mobile app was found to be effective in improving the knowledge, practice, and adherence to treatment of heart failure patients. There was no significant association between the knowledge, treatment adherence and not influenced by the selected variables except the practice scores are influenced by the regular follow up.
\end{abstract}


Poonam et.al. A study to develop and evaluate the effectiveness of a mobile app: samrudheart on self-care management of a patient with heart failure in terms of knowledge, practice, and adherence to treatment among heart failure patients in Safdarjung hospital, New Delhi.

Conclusion: Findings revealed that the mobile app: Samrudheart was found to be an effective strategy in improving the knowledge, practice, and adherence to treatment on self-care management of a patient with heart failure.

Keywords: Mobile App, Self-care management, Knowledge, Practice, Adherence, Heart Failure Patients.

\section{INTRODUCTION}

Chronic heart failure (HF), a progressive and debilitating disease, is increasing in epidemic proportions and affecting both the developed and the developing world. $^{[1]}$ Heart failure is associated with shorter life expectancy, increased frequency of hospitalization, and poor quality of life and is a major public health challenge even in India. ${ }^{[2]}$ Heart failure (HF) is one of the most prevalent cardiovascular diseases in the world which is associated with significant mortality, morbidity, and huge financial burden, particularly among an aging population. Rehospitalization remains a concern in the care of the heart failure patient which is largely associated with delay in symptoms recognition, treatment, diet non-compliance, and also lack of knowledge and skills in heart failure self-care. Guideline on HF emphasizes the importance of self-care in preventing symptoms and hospital readmission. ${ }^{[3]}$

HF self-care is defined as assisting the patients to manage their own care at home is a key component of $\mathrm{HF}$ management. Mobile health (mHealth) technology is defined as the "use of smartphones, tablets and other mobile devices to deliver health care and preventive health services" ${ }^{[4]}$

India was seen to be the capital of diabetes and coronary heart disease in the world. According to current estimates, India will soon have the highest number of heart disease cases in the world. ${ }^{[5]}$ According to the "Indian Heart Association", "50\% of all heart attacks in Indians occur under 50 years of age and $25 \%$ of all heart attacks in Indians occur under 40 years of age. ${ }^{[6]}$ Heart disease is increasing in the younger generation with a significant risk in both males and females. More and more young Indians are suffering from coronary artery disease, owing to their poor lifestyle, and if this continues the future looks even more dangerous. ${ }^{[7]}$

The World Health Organization (WHO) defined compliance and adherence as the degree to which a patient's behavior (such as taking medication, diet, and lifestyle changes) is consistent with the generally agreed therapeutic recommendations. The aims of the treatment for patients with HF include improving their clinical status, exercise capacity, and quality of life, preventing hospitalizations, and a reduction in total mortality. Adequate and current information that will allow them to make decisions about lifestyle changes and proper care of themselves should be provided to patients. ${ }^{[8]}$

Mobile technology offers ways to help with these challenges. through mobile health applications, sensors, medical devices, and remote patient monitoring products, there are avenues through which health care delivery can be improved. They enable easy-to-use access to tools like calorie counters, prescription reminders, appointment notices, medical references, and physician or hospital locators. These applications empower patients and health providers proactively to address medical conditions, through near real-time monitoring and treatment, no matter the location of the patient or health provider. ${ }^{[9]}$

\section{OBJECTIVES OF THE STUDY}

1. To develop and apply a mobile app: Samrudheart on self-care management of a patient with heart failure

2. To assess and evaluate the knowledge of heart failure patients related to self-care management of heart failure before and after the administration of a mobile app: Samrudheart. 
Poonam et.al. A study to develop and evaluate the effectiveness of a mobile app: samrudheart on self-care management of a patient with heart failure in terms of knowledge, practice, and adherence to treatment among heart failure patients in Safdarjung hospital, New Delhi.

3. To assess and evaluate the practice of heart failure patients related to self-care management of heart failure before and after the administration of a mobile app: Samrudheart.

4. To assess and evaluate the adherence to treatment of heart failure patients related to self-care management of heart failure before and after the administration of a mobile app: Samrudheart.

5. To find the relationship between mean post-test knowledge score and mean post-test practice score of heart failure patients about self-care management of heart failure after the administration of a mobile app: Samrudheart.

6. To find the relationship between mean post-test practice score and post-test adherence to treatment a score of heart failure patients regarding self-care management of heart failure after the administration of a mobile app: Samrudheart.

7. To find the relationship between mean post-test knowledge score and mean post-test adherence to treatment score of heart failure patients regarding self-care management of heart failure after the administration of a mobile app: Samrudheart.

8. To find the association between mean post-test knowledge scores of heart failure patients with selected variables.

9. To find out the association between mean post-test practices scores of heart failure patients with selected variables.

10. To find out the association between mean post-test adherences to treatment scores of heart failure patients with selected variables.

11. To determine the acceptability and utility of a mobile app: Samrudheart on self-care management of a patient with heart failure in terms of the opinion of Heart Failure patients.

\section{OPERATIONAL DEFINITION}

1. Develop:-In this study, it refers to prepare a mobile app: Samrudheart on selfcare management of a patient with heart failure to improve the knowledge, practice, and adherence to the treatment.

2. Evaluate: - In this study, it refers to the measurement of knowledge, practice, and adherence to the treatment of heart failure patients before and after administration of mobile app: Samrudheart on self-care management of heart failure.

3. Effectiveness: - In this study, effectiveness refers to the significant gain in knowledge, practice and adherence to treatment regarding self-care management of a patient with heart failure after the administration of mobile app: Samrudheart.

4. Knowledge: -In this study, knowledge refers to correct response to the items of structured knowledge questionnaire obtained regarding Self-Care management of Patients with Heart Failure.

$\begin{array}{lll}\text { Poor knowledge } & - & 0-7 \\ \text { Fair knowledge } & - & 8-14 \\ \text { Good knowledge } & - & 15-22 \\ \text { Very good knowledge } & - & 23-30\end{array}$

5. Practice: - In this study, practice refers to the expressed practice of a patient regarding the self-care management of a patient with heart failure at home as expressed by their responses to the items of the structured practice checklist.

$\begin{array}{lll}\text { Poor practices } & - & 0-10 \\ \text { Fair practices } & - & 11-20 \\ \text { Good practices } & - & 21-30\end{array}$

6. Adherence to the treatment: - In this study, adherence to treatment refers to the act to conform the recommendations made by the patients to timing and frequency of medication taking and regular follow-up.

$\begin{array}{lll}\text { Poor adherence } & = & 0-10 \\ \text { Fair adherence } & = & 11-20 \\ \text { Good adherence } & = & 21-30\end{array}$

7. Mobile app: Samrudheart on self-care management of heart failure: - In this study, A mobile app is based on selfinstructional reading material for achieving 
Poonam et.al. A study to develop and evaluate the effectiveness of a mobile app: samrudheart on self-care management of a patient with heart failure in terms of knowledge, practice, and adherence to treatment among heart failure patients in Safdarjung hospital, New Delhi.

pre-specified objectives; includes the instructional materials necessary for learning the self-care management of heart failure, app contains,

- Mobile app - Providing instruction material on self-care management of heart failure.

- Reminder- In this study, a reminder is mean a call to a patient once a day for 6 days for medication adherence and to follow the instruction of the app.

In this study name of the app is "Samrudheart Poonam" Link on the Google play store- for the android phone user.https://play.google.com/store/apps/deta il?id=codenticer.samrudheart

8. Self-care management: - In this study self-care management involves an active participation by a patient in his or her own health care decisions and interventions like adherence to medication, following a lowsalt diet, limiting alcohol consumption, avoiding tobacco, smoking, alcohol intake and daily monitoring of weight, other signs and symptoms that indicate worsening heart failure.

9. Heart failure: - In this study heart failure mean the patient who is having Ejection fraction of heart less than $40 \%$.

10. Selected variables: - In the present study, it denotes the certain factors that play a vital role in influencing knowledge, practice, and adherence after heart failure. these factors include:

- Age

- Sex

- Education status

- Family income

- BMI

- Duration of Illness

- Smoking

- Tobacco

- Alcohol Intake

- Diet

- Lifestyle
- Regular Follow-up

\section{METHODOLOGY}

Research approach- quasi-experimental approach

Research design- pre-test post-test control group design.

Dependent Variable: - knowledge, practice, and adherence to the treatment regarding self-care management of heart failure.

Independent variable: - Mobile app on self-care management of a patient with heart failure.

The extraneous variables: - In this study, the extraneous variables include Age, Sex, Education status, Family income, BMI, Duration of Illness, Smoking, Tobacco, Alcohol, Diet, Life Style, Regular Followup

The setting of the study: -Final study was conducted in cardiology OPD of Safdarjung Hospital, New Delhi.

Population: - In this study, the population comprised of the "Heart failure patients" attending cardiology OPD of Safdarjung Hospital, New Delhi".

Sample: - 60 heart failure patients (30 in experimental group and 30 in the control group)

Sample technique: - Sample was selected by purposive sampling technique and samples were randomly assigned to the 30 heart failure patient to the experimental and 30 heart failure patient control group.

\section{ETHICAL CONSIDERATION}

- Ethical permission was taken from the Ethical Committee of Rajkumari Amrit Kaur College of Nursing, New Delhi to conduct the research study.

- The pilot study was conducted to check the feasibility of the study and establish the reliability of the tool in Super Specialty Hospital Janakpuri New Delhi after obtaining permission from medical superintendent of the hospital.

- The final research study was conducted in VMMC and Safdarjung hospital New Delhi after obtaining the initial 
Poonam et.al. A study to develop and evaluate the effectiveness of a mobile app: samrudheart on self-care management of a patient with heart failure in terms of knowledge, practice, and adherence to treatment among heart failure patients in Safdarjung hospital, New Delhi.

administrative approval from the ethical committee and Medical Superintendent.

\section{Procedure:}

- Tool of the study - The tools used for the study were a structured knowledge questionnaire, structured practice checklist, Structured adherence to treatment rating scale and a structured opinionnaire, paper and pencil, and observation method were used to administer tool.

- The possible range of scores to be obtained by heart failure patient was from 0-30 for knowledge. The following categories were created for the interpretation of the knowledge scores obtained by heart failure patients. Hence, their scores were interpreted as: Categorization of knowledge scores:

○ Score between 23-30= Very good knowledge

○ Score between 15-22 = Good knowledge.

○ Score between 8-14 = Fair knowledge.

○ The score between 0-7 = Poor knowledge.

- The possible range of scores to be obtained by heart failure patient was from 0-30 for practice. The following categories were created for the interpretation of the practice scores obtained by heart failure patient. Hence, their scores were interpreted as:

Categorization of practice scores:

○ The score between 21-30 = Good practices.

○ The score between 11-20 = Fair practices.

$\circ$ The score between $0-10=$ Poor practices.

\section{SCORING}

For positive questions, scoring is done as follows

- Always- (2)

- Sometimes- (1)

- Never- (0)
For negative questions, scoring is done as follows

- Always- (0)

- Sometimes- (1)

- Never- (2)

- The possible range of scores to be obtained by heart failure patient was from 0-30 for treatment adherence. The following categories were created for the interpretation of the adherence to treatment scores obtained by heart failure patients. Hence, their scores were interpreted as:

Categorization of adherence:

○ The score between 21-30 = Good adherence

$\circ$ The score between $11-20=$ Fair adherence

$\circ$ The score between $0-10=$ Poor adherence

\section{SCORING}

For positive questions, scoring is done as follows

- Strongly agree- (2)

- Agree- (1)

- Disagree - (0)

For negative questions, scoring is done as follows

- Strongly agree- (0)

- Agree- (1)

- Disagree- (2)

\section{- DESCRIPTION OF STRUCTURED} OPINIONAIRE

The structured opinionnaire consisted of 10 items. Each item comprised of three responses that are "to a great extent", "to some extent" and "to very less extent",

- 21-30 marks = "to a great extent",

- 11-20 marks = "to some extent"

○ $0-10$ mark = "to a very little extent".

- To ensure the content validity of the tools, i.e. structured knowledge questionnaire, observational checklist for practice, adherence to treatment rating scale and opinionnaire was submitted to the 11 experts from the field of nursing and medical. The 
Poonam et.al. A study to develop and evaluate the effectiveness of a mobile app: samrudheart on self-care management of a patient with heart failure in terms of knowledge, practice, and adherence to treatment among heart failure patients in Safdarjung hospital, New Delhi.

experts were chosen based on their expertise, experience, qualification, and interest in the problem area.

- The internal consistency method by using Kuder Richardson-20 was used to compute the reliability of the structured knowledge questionnaire (0.78), for the reliability of the structured practice checklist by Cronbach's alpha formula (0.77) for adherence to treatment rating scale by Cronbach's alpha formula (0.79).

- The final data obtained was collected according to research design, the data were organized and interpreted by using both descriptive and inferential statistics according to objectives and hypothesis of the study.

\section{STATISTICAL ANALYSIS}

The data obtained would be analyzed using the following plan of analysis: -

- Demographic and health determinant data analysis by using frequencies and percentage

- Mean, Median \& Standard deviation of pre-test \& post-test knowledge scores.

- Mean, Median \& Standard deviation of pre-test \& post-test practice scores.

- Mean Median \& Standard deviation of pre-test \& post-test adherence to treatment scores.

- ' $t$ ' value to determine the significance of difference between the mean of pre-test \& post-test knowledge scores of patients on self-care management of a patient with heart failure.

- ' $t$ ' value to determine the significance of the difference between the mean of pretest \& post-test practice scores of patients on self-care management of a patient with heart failure.
- ' $t$ ' value to determine the significance of the difference between the mean of pretest \& post-test adherence to treatment scores of patients on self-care management of a patient with heart failure.

- Coefficient of correlation ( $\mathrm{r}$ value) to find out the relationship between posttest knowledge and practice scores.

- Coefficient of correlation ( $r$ value) to find out the relationship between posttest practice $\&$ adherence to treatment scores.

- Coefficient of correlation ( $\mathrm{r}$ value) to find out the relationship between posttest adherence to treatment \& knowledge scores.

- 'chi square' value would be computed to determine any significant association between post-test knowledge \& selected variables as age, sex, family income, education status, BMI, duration of heart failure, diet, smoking, tobacco, alcohol, lifestyle, and regular follow-up.

- 'chi square' value would be computed to determine any significant association between post-test practice \& selected variables as age, sex, family income, education status, BMI, duration of heart failure, diet, smoking, tobacco, alcohol, lifestyle, and regular follow-up.

- 'chi square' value would be computed to determine any significant association between post-test adherence to treatment $\&$ selected variables as age, sex, family income, education status, BMI, duration of heart failure, diet, smoking, tobacco, alcohol, lifestyle, and regular follow-up.

\section{RESULTS}

TABLE -1: FREQUENCY AND PERCENTAGE DISTRIBUTION OF DEMOGRAPHIC DATA OF SAMPLE CHARACTERISTIC, $\mathrm{N}=60$

\begin{tabular}{|c|c|c|c|c|c|c|c|}
\hline \multirow[t]{2}{*}{ S. NO } & \multirow[t]{2}{*}{ PATIENTS CHARACTERISTICS } & \multicolumn{2}{|c|}{ EXPERIMENTAL GROUP } & \multicolumn{2}{|c|}{ CONTROL GROUP } & \multicolumn{2}{|c|}{ TOTAL } \\
\hline & & $\mathbf{F}$ & $\%$ & $\mathbf{F}$ & $\%$ & f & $\%$ \\
\hline 1. & Gender & & & & & & \\
\hline 1.1 & Male & 17 & $57 \%$ & 21 & $70 \%$ & 38 & $63 \%$ \\
\hline 1.2 & Female & 13 & $43 \%$ & 9 & $30 \%$ & 22 & $37 \%$ \\
\hline
\end{tabular}


Poonam et.al. A study to develop and evaluate the effectiveness of a mobile app: samrudheart on self-care management of a patient with heart failure in terms of knowledge, practice, and adherence to treatment among heart failure patients in Safdarjung hospital, New Delhi.

\begin{tabular}{|c|c|c|c|c|c|c|c|}
\hline \multicolumn{8}{|c|}{ Table 1 Continued... } \\
\hline 2. & Age(years) & & & & & & \\
\hline 2.1 & $20-30$ & 2 & $7 \%$ & 2 & $6.67 \%$ & 4 & $5 \%$ \\
\hline 2.2 & $31-40$ & 4 & $13 \%$ & 5 & $16.67 \%$ & 9 & $15 \%$ \\
\hline 2.3 & $41-50$ & 10 & $33 \%$ & 8 & $26.67 \%$ & 18 & $30 \%$ \\
\hline 2.4 & $51-60$ & 14 & $46.6 \%$ & 15 & $50.00 \%$ & 29 & $50 \%$ \\
\hline 3. & Education & & & & & & \\
\hline 3.1 & $5^{\text {th }}-8^{\text {th }}$ class & 9 & $30 \%$ & 14 & $46.67 \%$ & 23 & $38 \%$ \\
\hline 3.2 & $9^{\text {th }}-12^{\text {th }}$ class & 14 & $47 \%$ & 11 & $36.67 \%$ & 25 & $42 \%$ \\
\hline 3.3 & Graduation & 4 & $1 \%$ & 2 & $6.67 \%$ & 6 & $10 \%$ \\
\hline 3.4 & Post-Graduation and Above & 3 & $10 \%$ & 3 & $10.00 \%$ & 6 & $10 \%$ \\
\hline 4 & Family Income in Rs. & & & & & & \\
\hline 4.1 & Below 5000 & 7 & $23 \%$ & 10 & $33 \%$ & 17 & $28 \%$ \\
\hline 4.2 & $5001-10000$ & 4 & $13 \%$ & 5 & $17 \%$ & 9 & $15 \%$ \\
\hline 4.3 & $10001-20000$ & 11 & $37 \%$ & 8 & $27 \%$ & 19 & $32 \%$ \\
\hline 4.4 & Above 20000 & 8 & $27 \%$ & 7 & $23 \%$ & 15 & $25 \%$ \\
\hline
\end{tabular}

TABLE- 2: FREQUENCY AND PERCENTAGE DISTRIBUTION OF HEALTH DETERMINANT DATA OF SAMPLE CHARACTERISTIC. $\quad \mathrm{N}=60$

\begin{tabular}{|c|c|c|c|c|c|c|c|}
\hline \multirow[t]{2}{*}{ S.NO } & \multirow[t]{2}{*}{ PATIENTS CHARACTERISTICS } & \multicolumn{2}{|c|}{ EXPERIMENTAL GROUP } & \multicolumn{2}{|c|}{ CONTROL GROUP } & \multicolumn{2}{|c|}{ Total } \\
\hline & & $\mathbf{F}$ & $\%$ & $\mathbf{F}$ & $\% \mathrm{~S}$ & $\mathbf{F}$ & $\%$ \\
\hline 1. & BMI & & & & & & \\
\hline 1.1 & Underweight (below 18.5) & 2 & $7 \%$ & 4 & $13 \%$ & 6 & $10 \%$ \\
\hline 1.2 & Average weight (18.5to 24.9) & 20 & $67 \%$ & 20 & $67 \%$ & 40 & $67 \%$ \\
\hline 1.3 & Overweight (above 24.9) & 8 & $27 \%$ & 6 & $20 \%$ & 14 & $23 \%$ \\
\hline 2. & DURATION OF ILLNESS & & & & & & \\
\hline 2.1 & $<3$ months & 5 & $17 \%$ & 3 & $10 \%$ & 8 & $13 \%$ \\
\hline 2.2 & 3-1 year & 9 & $30 \%$ & 3 & $10 \%$ & 12 & $20 \%$ \\
\hline 2.3 & $1-3$ years & 7 & $23 \%$ & 11 & $37 \%$ & 18 & $30 \%$ \\
\hline 2.4 & $>3$ years & 9 & $30 \%$ & 13 & $43 \%$ & 22 & $37 \%$ \\
\hline 3. & Lifestyle & & & & & & \\
\hline 3.1 & Sedentary & 18 & $60 \%$ & 13 & $43 \%$ & 31 & $52 \%$ \\
\hline 3.2 & Active & 12 & $40 \%$ & 17 & $57 \%$ & 29 & $48 \%$ \\
\hline 4. & Smoking & & & & & & \\
\hline 4.1 & Yes & 16 & $53 \%$ & 17 & $57 \%$ & 33 & $55 \%$ \\
\hline 4.2 & No & 14 & $47 \%$ & 13 & $43 \%$ & 27 & $45 \%$ \\
\hline 5. & Tobacco & & & & & & \\
\hline 5.1 & Yes & 11 & $37 \%$ & 8 & $27 \%$ & 19 & $32 \%$ \\
\hline 5.2 & No & 19 & $63 \%$ & 22 & $73 \%$ & 41 & $68 \%$ \\
\hline 6. & Alcohol & & & & & & \\
\hline 6.1 & Yes & 13 & $43 \%$ & 15 & $50 \%$ & 28 & $47 \%$ \\
\hline 6.2 & No & 17 & $57 \%$ & 15 & $50 \%$ & 32 & $53 \%$ \\
\hline 7. & Diet & & & & & & \\
\hline 7.1 & Vegetarian & 12 & $40 \%$ & 6 & $20 \%$ & 18 & $30 \%$ \\
\hline 7.2 & Non-Vegetarian & 15 & $50 \%$ & 20 & $67 \%$ & 35 & $58 \%$ \\
\hline 7.3 & Eggetarian & 3 & $10 \%$ & 4 & $13 \%$ & 7 & $12 \%$ \\
\hline 8. & Follow Up & & & & & & \\
\hline 8.1 & Rarely & 4 & $13 \%$ & 5 & $17 \%$ & 9 & $15 \%$ \\
\hline 8.2 & Unscheduled & 12 & $40 \%$ & 8 & $27 \%$ & 20 & $33 \%$ \\
\hline 8.3 & In emergency & 8 & $27 \%$ & 8 & $27 \%$ & 16 & $27 \%$ \\
\hline 8.4 & Scheduled & 6 & $20 \%$ & 9 & $30 \%$ & 15 & $25 \%$ \\
\hline
\end{tabular}

TABLE -3: Mean, median, standard deviation of pre-test and post-test knowledge scores on self-care management of a patient with heart failure in experimental and control group. $\mathrm{N}=60$

\begin{tabular}{|c|c|c|c|c|c|}
\hline GROUP & KNOWLEDGE SCORE (30) & SCORE RANGE & MEAN & MEDIAN & STANDARD DEVIATION \\
\hline \multirow{2}{*}{$\begin{array}{l}\text { Experimental group } \\
n=30\end{array}$} & Pre-test & $11-20$ & 14.1 & 14 & 2.26 \\
\hline & Post-test & $17-25$ & 21.6 & 22 & 1.85 \\
\hline $\begin{array}{l}\text { Control group } \\
\mathrm{n}=30\end{array}$ & Pre-test & $11-21$ & 14.07 & 14 & 2.12 \\
\hline
\end{tabular}

TABLE: 4: Mean, mean difference (MD), standard deviation difference $\left(S D_{d}\right)$, standard error of mean difference (SE value of the pre-test and post-test knowledge scores of heart failure in a patient of experimental group. $n=30$

\begin{tabular}{|c|c|c|c|c|c|c|}
\hline GROUP & $\begin{array}{l}\text { KNOWLEDGE SCORE } \\
(30)\end{array}$ & MEAN & $\begin{array}{l}\text { MEAN DIFFERENCE } \\
\text { (MD) }\end{array}$ & $\mathbf{S D}_{\mathrm{d}}$ & $\mathbf{S E}_{\mathbf{M D}}$ & $\begin{array}{l}t \text { "t" } \\
\text { VALUE }\end{array}$ \\
\hline \multirow[t]{2}{*}{ Experimental group } & Pre-test & 14.1 & \multirow[t]{2}{*}{7.5} & \multirow[t]{2}{*}{1.76} & \multirow[t]{2}{*}{0.32} & \multirow[t]{2}{*}{$23.38 *$} \\
\hline & Post-test & 21.6 & & & & \\
\hline
\end{tabular}

The data presented in table (4) shows that the mean post-test knowledge scores of the experimental group (21.6) are higher than the mean pre-test knowledge 
Poonam et.al. A study to develop and evaluate the effectiveness of a mobile app: samrudheart on self-care management of a patient with heart failure in terms of knowledge, practice, and adherence to treatment among heart failure patients in Safdarjung hospital, New Delhi.

scores of the experimental group (14.1) with a mean difference of (7.5). The calculated " $t$ " value (23.38) for df 29 was found to be statistically significant at 0.05 and 0.01 levels of significance. Thus, it is established that the difference obtained in the mean pretest and post-test knowledge scores of the experimental group is a true difference and not by chance.

TABLE- 5: Mean, mean difference (MD), standard deviation difference $\left(\mathrm{SD}_{\mathrm{d}}\right)$, standard error of mean difference $\left(\mathrm{SE} \mathrm{MD}_{\mathrm{MD}}\right)$, and " $\mathrm{t}$ " value of the post-test knowledge scores of heart failure a patient of experimental and control group. $N=60$

\begin{tabular}{|c|c|c|c|c|c|c|c|}
\hline GROUP & $\begin{array}{l}\text { KNOWLEDGE SCORES } \\
(30)\end{array}$ & $\begin{array}{l}\text { SCORE } \\
\text { RANGE }\end{array}$ & MEAN & $\begin{array}{l}\text { MEAN DIFFERENCE } \\
\text { (MD) }\end{array}$ & $\mathbf{S D}_{\mathrm{d}}$ & $\mathbf{S E}_{\mathbf{M D}}$ & $\begin{array}{l}\text { "t" } \\
\text { value }\end{array}$ \\
\hline $\begin{array}{l}\text { Experimental } \\
\text { group } \\
\mathrm{n}=30\end{array}$ & Post-test & $17-25$ & 21.6 & \multirow[t]{2}{*}{6.9} & \multirow[t]{2}{*}{1.55} & \multirow[t]{2}{*}{0.4} & \multirow[t]{2}{*}{ 17.01* } \\
\hline $\begin{array}{l}\text { Control } \\
\text { group } \\
n=30\end{array}$ & Post-test & $11-21$ & 14.7 & & & & \\
\hline
\end{tabular}

$$
* t \text { value for } d f(58) \text { level }=2.39, p<0.01=\text { significance at } 0.01 \text { level. }
$$

The data are given in table (5) shows that the mean post-test knowledge scores (21.6) of heart failure patient in the experimental group is higher than the mean post-test knowledge scores of control group (14.7) scores with a mean difference of (6.9). The calculated "t" value (17.01) for $\mathrm{df}$
58 was found to be statistically significant at 0.05 and 0.01 levels of significance. Thus, it is established that the difference obtained in the mean post-test knowledge scores of an experimental and control group is a true difference and not by chance.

TABLE- 6: Mean, a median, standard deviation of pre-test and post-test practice scores on self-care management of heart failure in experimental and control group. $\mathrm{N}=60$

\begin{tabular}{|l|l|l|l|l|l|}
\hline GROUP & PRACTICE SCORE (30) & SCORE RANGE & MEAN & MEDIAN & STANDARD DEVIATION \\
\hline \multirow{2}{*}{$\begin{array}{l}\text { Experimental group } \\
\mathrm{n}=30\end{array}$} & Pre-test & $10-20$ & 15.5 & 16 & 2.25 \\
\cline { 2 - 6 } & Post-test & $18-26$ & 21.4 & 21.5 & 1.99 \\
\hline \multirow{2}{*}{$\begin{array}{l}\text { Control group } \\
\mathrm{n}=30\end{array}$} & Pre-test & $11-19$ & 15.1 & 15 & 2.50 \\
\cline { 2 - 6 } & Post-test & $11-20$ & 15.13 & 15 & 2.33 \\
\hline
\end{tabular}

TABLE: - 7: Mean, mean difference (MD), standard deviation difference $\left(S_{\mathrm{d}}\right)$, standard error of mean difference (SE $\left.{ }_{M D}\right)$, and " $t$ " value of the pre-test and post-test practice scores of heart failure a patient of the experimental group. $n=30$

\begin{tabular}{|c|c|c|c|c|c|c|c|}
\hline GROUP & $\begin{array}{l}\text { PRACTICE SCORE } \\
(30)\end{array}$ & Score range & MEAN & $\begin{array}{l}\text { MEAN DIFFERENCE } \\
\text { (MD) }\end{array}$ & $S D_{d}$ & $\mathbf{S E}_{\mathbf{M D}}$ & $\begin{array}{l}\text { "t"' } \\
\text { VALUE }\end{array}$ \\
\hline \multirow[t]{2}{*}{ Experimental group } & PRE-TEST & $10-21$ & 15.5 & \multirow[t]{2}{*}{5.93} & \multirow[t]{2}{*}{1.89} & \multirow[t]{2}{*}{0.35} & \multirow[t]{2}{*}{$16.8^{*}$} \\
\hline & POST-TEST & $11-19$ & 21.43 & & & & \\
\hline
\end{tabular}

The data presented in table (7) shows that the mean post-test practice scores of the experimental group (21.43) are higher than the mean pre-test practice scores of the experimental group (15.5) with a mean difference of (5.93). The calculated "t" value (16.8) is more than the table value for df 29 was found to be statistically significant at 0.05 and 0.01 level of significance. Thus, it is established that the difference obtained in the mean pre-test and post-test practice scores of the experimental group are a true difference and not by chance.

Table - 8: Mean, mean difference (MD), standard deviation difference (SD ${ }_{d}$ ), standard error of mean difference (SE ${ }_{M D}$ ), and " $t$ " value of the post-test practice scores of heart failure a patient of experimental and control group. $\mathrm{N}=60$

\begin{tabular}{|c|c|c|c|c|c|c|c|}
\hline GROUP & $\begin{array}{l}\text { PRACTICE SCORE } \\
(30)\end{array}$ & $\begin{array}{l}\text { Score } \\
\text { range }\end{array}$ & MEAN & $\begin{array}{l}\text { MEAN DIFFERENCE } \\
\text { (MD) }\end{array}$ & $\mathbf{S D}_{\mathrm{d}}$ & $\mathbf{S E}_{\mathrm{MD}}$ & $\begin{array}{l}\text { "t" } \\
\text { value }\end{array}$ \\
\hline $\begin{array}{ll}\text { Experimental } & \text { Group } \\
\mathrm{n}=30 & \end{array}$ & Post-test & $18-26$ & 21.43 & \multirow[t]{2}{*}{6.27} & \multirow[t]{2}{*}{0.86} & \multirow[t]{2}{*}{0.22} & \multirow[t]{2}{*}{$28.33 *$} \\
\hline Control group $n=30$ & Post-test & $11-20$ & 15.13 & & & & \\
\hline
\end{tabular}

The data are given in table (8) shows that the mean post-test practice scores
(21.43) of heart failure patient in the experimental group is higher than the mean 
Poonam et.al. A study to develop and evaluate the effectiveness of a mobile app: samrudheart on self-care management of a patient with heart failure in terms of knowledge, practice, and adherence to treatment among heart failure patients in Safdarjung hospital, New Delhi.

post-test practice scores of the control group (15.13) scores with a mean difference of (6.27). The calculated " $t$ " value (28.33) for df 58 was found to be statistically significant at 0.05 and 0.01 levels of significance. Thus, it is established that the difference obtained in the mean post-test practice scores of experimental group and control group is a true difference and not by chance.

TABLE - 9: MEAN, MEDIAN, STANDARD DEVIATION OF PRE-TEST AND POST-TEST ADHERENCE TO TREATMENT SCORES ON SELF-CARE MANAGEMENT OF A PATIENT WITH HEART FAILURE IN EXPERIMENTAL AND CONTROL GROUP. N=60

\begin{tabular}{|l|l|l|l|l|l|}
\hline GROUP & ADHERENCE SCORE (30) & SCORING RANGE & MEAN & MEDIAN & STANDARD DEVIATION \\
\hline \multirow{2}{*}{$\begin{array}{l}\text { Experimental group } \\
\mathrm{n}=30\end{array}$} & Pre-test & $12-19$ & 15 & 15 & 2.13 \\
\cline { 2 - 6 } & Post-test & $20-26$ & 22.9 & 23 & 1.8 \\
\hline \multirow{2}{*}{$\begin{array}{l}\text { Control group } \\
\mathrm{n}=30\end{array}$} & Pre-test & $12-19$ & 14.87 & 14 & 2.15 \\
\cline { 2 - 6 } & Post-test & $12-22$ & 16.4 & 16 & 2.3 \\
\hline
\end{tabular}

TABLE: - 10: Mean, mean difference (MD), standard deviation difference $\left(\mathrm{SD}_{\mathrm{d}}\right)$, standard error of mean difference (SE $\left.\mathrm{MD}\right)$ and "t " value of the pre-test and post-test adherence scores of heart failure in a patient of experimental group. $n=30$

\begin{tabular}{|l|l|l|l|l|l|l|l|}
\hline GROUP & ADHERENCE SCORE & Score range & MEAN & Mean difference (MD) & SD $_{\mathbf{d}}$ & SE $_{\mathbf{M D}}$ & "t $^{\prime}$ VALUE \\
\hline $\begin{array}{l}\text { Experimental group } \\
(\mathrm{n}=30)\end{array}$ & PRE-TEST & $12-19$ & 15 & 7.9 & 2.02 & 0.37 & $28.4 *$ \\
\cline { 2 - 4 } & POST-TEST & $20-26$ & 22.9 & & & \\
\hline
\end{tabular}

The data presented in table (10) shows that the mean post-test adherence to treatment scores of the experimental group (22.9) is higher than the mean pre-test adherence to treatment scores of the experimental group (15) with a mean difference of (7.9). The calculated " $t$ " value (28.9) is more than the table value for df 29 was found to be statistically significant at 0.05 and 0.01 level of significance as well. Thus, it is established that the difference obtained in the mean pre-test and post-test adherence to treatment scores of the experimental group is a true difference and not by chance.

TABLE - 11: Mean, a median difference (MD), standard deviation difference (SD $\left.{ }_{d}\right)$, standard error of mean difference (SE $\left.{ }_{M D}\right)$, and " $t$ " value of the post-test adherence to treatment scores of heart failure a patient of the experimental and control group. $N=60$

\begin{tabular}{|c|c|c|c|c|c|c|c|}
\hline GROUP & ADHERENCE SCORE & Score range & MEAN & Mean difference (MD) & $\mathbf{S D}_{\mathrm{d}}$ & $\mathrm{SE}_{\mathrm{MD}}$ & "tt" value \\
\hline Experimental Group, $n=30$ & Post-test & $20-26$ & 22.9 & \multirow[t]{2}{*}{6.5} & \multirow[t]{2}{*}{1} & \multirow[t]{2}{*}{0.26} & \multirow[t]{2}{*}{$25.08^{*}$} \\
\hline Control group $n=30$ & Post-test & $12-22$ & 16.4 & & & & \\
\hline
\end{tabular}

The data are given in table (11) shows that the mean post-test adherence to treatment scores (22.9) of heart failure a patient in the experimental group is higher than the mean post-test adherence to treatment scores of the control group (15.13) scores with a mean difference of (6.27). The calculated " $t$ " value (25.08) is more than the table value for df 58 was found to be statistically significant at 0.05 and 0.01 level of significance as well. Thus, it is established that the difference obtained in the mean post-test adherence to treatment scores of the experimental group and a control group is a true difference and not by chance.

TABLE- 12: Karl Pearson coefficient of correlation between post-test knowledge scores and post-test practice scores of adolescent scores of a patient with heart failure of the experimental group. $n=30$

\begin{tabular}{|l|l|l|l|l|}
\hline Group & Variables & Mean & SD & "r" value \\
\hline Experimental group & Knowledge scores & 21.63 & 1.89 & $0.99 *$ \\
\cline { 2 - 3 } & Practice scores & 21.43 & 1.75 & \\
\hline
\end{tabular}

TABLE- 13: Karl Pearson coefficient of correlation between post-test practice scores and post-test adherence to treatment scores of adolescent scores of a patient with heart failure of the experimental group. $n=30$

\begin{tabular}{|l|l|l|l|l|}
\hline Group & Variables & Mean & SD & "r" value \\
\hline Experimental group & Practice scores & 21.43 & 1.81 & $0.98 *$ \\
\cline { 2 - 3 } & Adherence to treatment scores & 22.9 & 1.75 & \\
\hline & $* r$ value for $d f(28)$ " $r$ " $=0.296$, significant at 0.05 level. \\
& ${ }^{r}$ value for df $(28)$ " $r$ " $=0.409$, significant at 0.01 level.
\end{tabular}


Poonam et.al. A study to develop and evaluate the effectiveness of a mobile app: samrudheart on self-care management of a patient with heart failure in terms of knowledge, practice, and adherence to treatment among heart failure patients in Safdarjung hospital, New Delhi.

TABLE- 14: Karl Pearson coefficient of correlation between post-test knowledge scores and post-test adherence scores of a patient with heart failure of experimental group. $n=30$

\begin{tabular}{|l|l|l|l|l|}
\hline Group & Variables & Mean & SD & $\begin{array}{l}\text { "r" } \\
\text { value }\end{array}$ \\
\hline Experimental group & Knowledge scores & 21.6 & 1.89 & $0.98^{*}$ \\
\cline { 2 - 3 } & Adherence to treatment scores & 22.9 & 1.81 & \\
\hline \multicolumn{3}{|l|}{ *r value for $d f(28)$ " $r$ " $=0.296$, significant at 0.05 level. $^{*}{ }^{*}$ value for $d f(28)$ " $r$ " $=0.409$, significant at 0.01 level. }
\end{tabular}

TABLE- 15: CHI-SQUARE VALUE SHOWING ASSOCIATION BETWEEN POST-TEST KNOWLEDGE SCORES WITH SELECTED VARIABLES OF HEART FAILURE A PATIENT OF EXPERIMENTAL GROUP. $\mathbf{n}=30$

\begin{tabular}{|c|c|c|c|c|c|c|c|}
\hline \multirow[t]{2}{*}{ S.no } & \multirow{2}{*}{$\begin{array}{l}\text { Sample } \\
\text { characteristics }\end{array}$} & \multicolumn{2}{|c|}{ Knowledge scores } & \multicolumn{2}{|l|}{ chi-square } & \multirow[t]{2}{*}{ df } & \multirow{2}{*}{$\begin{array}{l}\text { Significant/Not } \\
\text { significant }\end{array}$} \\
\hline & & $\begin{array}{l}\text { Below } \\
\text { median(f) }\end{array}$ & $\begin{array}{l}\text { Above } \\
\text { median(f) }\end{array}$ & $\begin{array}{l}\text { Computed } \\
\text { value }\end{array}$ & $\begin{array}{l}\text { Table } \\
\text { value }\end{array}$ & & \\
\hline \multirow[t]{5}{*}{1} & Age & & & 4.630 & 7.81 & 3 & Not significant \\
\hline & $20-30$ & 1 & 1 & & & & \\
\hline & $31-40$ & 2 & 2 & & & & \\
\hline & $41-50$ & 2 & 8 & & & & \\
\hline & $51-60$ & 9 & 5 & & & & \\
\hline \multirow[t]{3}{*}{2} & Sex & & & 0.4751 & 3.84 & 1 & Not significant \\
\hline & Male & 7 & 10 & & & & \\
\hline & Female & 7 & 6 & & & & \\
\hline \multirow[t]{4}{*}{3} & BMI & & & 1 & 5.99 & 2 & Not significant \\
\hline & Underweight & 2 & 1 & & & & \\
\hline & Average weight & 7 & 12 & & & & \\
\hline & Overweight & 5 & 3 & & & & \\
\hline \multirow[t]{5}{*}{4} & Family income & & & 4.630 & 7.81 & 3 & Not significant \\
\hline & $<5000$ & 4 & 3 & & & & \\
\hline & Between 5001-10000 & 3 & 1 & & & & \\
\hline & Between 10001-20000 & 5 & 6 & & & & \\
\hline & $>20001$ & 2 & 6 & & & & \\
\hline \multirow[t]{5}{*}{5} & Educational status & & & 1.604 & 7.81 & 3 & Not significant \\
\hline & 5th-8th pass & 5 & 4 & & & & \\
\hline & 9th-12th pass & 6 & 8 & & & & \\
\hline & Graduates & 1 & 3 & & & & \\
\hline & Postgraduates & 2 & 1 & & & & \\
\hline \multirow[t]{3}{*}{6} & Lifestyle factors & & & 0.0893 & 3.84 & 1 & Not significant \\
\hline & Sedentary & 8 & 10 & & & & \\
\hline & Active & 6 & 6 & & & & \\
\hline \multirow[t]{3}{*}{7} & Smoking & & & 0.1531 & 3.84 & 1 & Not significant \\
\hline & Yes & 8 & 8 & & & & \\
\hline & No & 6 & 8 & & & & \\
\hline \multirow[t]{3}{*}{8} & Tobacco & & & 0.0893 & 3.84 & 1 & Not significant \\
\hline & Yes & 6 & 6 & & & & \\
\hline & No & 8 & 10 & & & & \\
\hline \multirow[t]{3}{*}{9} & Alcohol & & & 1.4286 & 3.84 & 1 & Not significant \\
\hline & Yes & 4 & 8 & & & & \\
\hline & No & 10 & 8 & & & & \\
\hline \multirow[t]{4}{*}{10} & Diet & & & 3.2204 & 5.99 & 2 & Not significant \\
\hline & Vegetarian & 3 & 8 & & & & \\
\hline & Non-vegetarian & 8 & 7 & & & & \\
\hline & Eggetarian & 3 & 1 & & & & \\
\hline \multirow[t]{5}{*}{11} & Duration of illness & & & 2.4745 & 7.81 & 3 & Not significant \\
\hline & $<3$ month & 2 & 3 & & & & \\
\hline & 3 month-1 year & 4 & 5 & & & & \\
\hline & $1-3$ year & 2 & 5 & & & & \\
\hline & $>3$ years & 6 & 3 & & & & \\
\hline \multirow[t]{5}{*}{12} & Regular follow up & & & 3.7013 & 7.81 & 3 & Not significant \\
\hline & a Rarely & 1 & 4 & & & & \\
\hline & unscheduled & & 7 & & & & \\
\hline & c In emergency & 6 & 3 & & & & \\
\hline & Regular & 3 & 2 & & & & \\
\hline
\end{tabular}

This shows that there is no significant association between the post-test knowledge scores of heart failure patient in the experimental group and selected variables 
Poonam et.al. A study to develop and evaluate the effectiveness of a mobile app: samrudheart on self-care management of a patient with heart failure in terms of knowledge, practice, and adherence to treatment among heart failure patients in Safdarjung hospital, New Delhi.

TABLE- 16: Chi-square value showing the association between post-test practice scores with selected variables of heart failure a patient of the experimental group. $n=30$

\begin{tabular}{|c|c|c|c|c|c|c|c|}
\hline \multirow[t]{2}{*}{ S.no } & \multirow[t]{2}{*}{ Sample characteristics } & \multicolumn{2}{|l|}{ Practice scores } & \multicolumn{2}{|l|}{ chi-square } & \multirow[t]{2}{*}{ df } & \multirow{2}{*}{$\begin{array}{l}\text { Significant/ } \\
\text { Not Significant }\end{array}$} \\
\hline & & $\begin{array}{l}\text { Below median } \\
\text { (f) }\end{array}$ & $\begin{array}{l}\text { Above median } \\
\text { (f) }\end{array}$ & $\begin{array}{l}\text { Computed } \\
\text { value }\end{array}$ & Table value & & \\
\hline \multirow[t]{5}{*}{1} & Age & & & 0.69 & 7.81 & 3 & Not significant \\
\hline & $20-30$ & 1 & 1 & & & & \\
\hline & $31-40$ & 2 & 2 & & & & \\
\hline & $41-50$ & 4 & 6 & & & & \\
\hline & $51-60$ & 8 & 6 & & & & \\
\hline \multirow[t]{3}{*}{2} & Sex & & & 1.22 & 3.84 & 1 & Not significant \\
\hline & Male & 10 & 7 & & & & \\
\hline & Female & 5 & 8 & & & & \\
\hline \multirow[t]{4}{*}{3} & BMI & & & 0.89 & 5.99 & 2 & Not significant \\
\hline & Underweight & 2 & 1 & & & & \\
\hline & Average weight & 10 & 9 & & & & \\
\hline & Overweight & 3 & 5 & & & & \\
\hline \multirow[t]{5}{*}{4} & Family income & & & 1.46 & 7.81 & 2 & Not significant \\
\hline & $<5000$ & 3 & 4 & & & & \\
\hline & $\begin{array}{l}\text { Between } \\
5001-10000\end{array}$ & 2 & 2 & & & & \\
\hline & Between 10001-20000 & 7 & 4 & & & & \\
\hline & $>20001$ & 3 & 5 & & & & \\
\hline \multirow[t]{5}{*}{5} & Educational status & & & 1.73 & 7.81 & 3 & Not significant \\
\hline & 5th-8th pass & 5 & 4 & & & & \\
\hline & 9th-12th pass & 6 & 8 & & & & \\
\hline & Graduates & 3 & 1 & & & & \\
\hline & Postgraduates & 1 & 2 & & & & \\
\hline \multirow[t]{3}{*}{6} & Lifestyle factors & & & 0 & 3.84 & 1 & Not significant \\
\hline & Sedentary & 9 & 9 & & & & \\
\hline & Active & 6 & 6 & & & & \\
\hline \multirow[t]{3}{*}{7} & Smoking & & & 0.54 & 3.84 & 1 & Not significant \\
\hline & Yes & 9 & 7 & & & & \\
\hline & No & 6 & 8 & & & & \\
\hline \multirow[t]{3}{*}{8} & Tobacco & & & 0.55 & 3.84 & 1 & Not significant \\
\hline & Yes & 5 & 7 & & & & \\
\hline & No & 10 & 8 & & & & \\
\hline \multirow[t]{3}{*}{9} & Alcohol & & & 0 & 3.84 & 1 & Not significant \\
\hline & Yes & 6 & 6 & & & & \\
\hline & No & 9 & 9 & & & & \\
\hline \multirow[t]{4}{*}{10} & Diet & & & 1.42 & 5.99 & 2 & Not significant \\
\hline & Vegetarian & 7 & 4 & & & & \\
\hline & Non-veg & 6 & 9 & & & & \\
\hline & Eggetarian & 2 & 2 & & & & \\
\hline \multirow[t]{5}{*}{11} & Duration of illness & & & 1.45 & 7.81 & 3 & Not significant \\
\hline & $<3$ months & 3 & 2 & & & & \\
\hline & 3 month-1 year & 5 & 4 & & & & \\
\hline & 1-3 year & 4 & 3 & & & & \\
\hline & $>3$ years & 3 & 6 & & & & \\
\hline \multirow[t]{5}{*}{12} & Regular follow up & & & 8.26 & 7.81 & 3 & Significant \\
\hline & Rarely & 4 & 1 & & & & \\
\hline & unscheduled & 7 & 4 & & & & \\
\hline & In-emergency & 1 & 8 & & & & \\
\hline & Regular & 3 & 2 & & & & \\
\hline
\end{tabular}

This shows that there is no significant association between the post-test practice scores of heart failure patients in the experimental group and selected variables except regular follow-up.

TABLE- 17: Chi-square value showing the association between post-test adherence to treatment scores with selected variables of heart failure a patient of experimental group. $n=30$

\begin{tabular}{|c|c|c|c|c|c|c|c|}
\hline \multirow[t]{2}{*}{ S.no } & \multirow[t]{2}{*}{ Sample characteristics } & \multicolumn{2}{|l|}{ Adherence score } & \multirow[t]{2}{*}{ chi-square } & \multirow[b]{2}{*}{ TABLE VALUE } & \multirow[b]{2}{*}{ df } & \multirow{2}{*}{$\begin{array}{l}\text { Significant/ } \\
\text { Not Significan }\end{array}$} \\
\hline & & Below median(f) & Above median(f) & & & & \\
\hline \multirow[t]{5}{*}{1} & Age & & & 1.56 & 7.81 & 3 & Not Significant \\
\hline & $20-30$ & 1 & 1 & & & & \\
\hline & $31-40$ & 1 & 3 & & & & \\
\hline & $41-50$ & 6 & 4 & & & & \\
\hline & $51-60$ & 6 & 8 & & & & \\
\hline \multirow[t]{3}{*}{2} & Sex & & & 0.002 & 3.84 & 1 & Not Significant \\
\hline & Male & 8 & 9 & & & & \\
\hline & Female & 6 & 7 & & & & \\
\hline
\end{tabular}


Poonam et.al. A study to develop and evaluate the effectiveness of a mobile app: samrudheart on self-care management of a patient with heart failure in terms of knowledge, practice, and adherence to treatment among heart failure patients in Safdarjung hospital, New Delhi.

\begin{tabular}{|c|c|c|c|c|c|c|c|}
\hline \multicolumn{8}{|c|}{ Table: 17: Continued ... } \\
\hline \multirow[t]{4}{*}{3} & BMI & & & 0.25 & 5.99 & 2 & Not Significant \\
\hline & Underweight & 1 & 2 & & & & \\
\hline & Average weight & 9 & 10 & & & & \\
\hline & Overweight & 4 & 4 & & & & \\
\hline \multirow[t]{5}{*}{4} & Family income & & & 0.10 & 5.99 & 2 & Not Significant \\
\hline & Below 5000 & 3 & 0 & & & & \\
\hline & Between 5001-10000 & 1 & 3 & & & & \\
\hline & Between 10001-20000 & 1 & 2 & & & & \\
\hline & Above 20001 & & & & & & \\
\hline \multirow[t]{5}{*}{5} & Educational status & & & 0.31 & 7.81 & 3 & Not Significant \\
\hline & 5th-8th pass & 4 & 5 & & & & \\
\hline & 9th-12th pass & 7 & 7 & & & & \\
\hline & Graduates & 2 & 2 & & & & \\
\hline & Postgraduates & 1 & 2 & & & & \\
\hline \multirow[t]{3}{*}{6} & Lifestyle factors & & & 1.09 & 3.84 & 1 & Not Significant \\
\hline & Sedentary & 7 & 11 & & & & \\
\hline & Active & 7 & 5 & & & & \\
\hline \multirow[t]{3}{*}{7} & Smoking & & & 0.15 & 3.84 & 1 & Not Significant \\
\hline & Yes & 8 & 8 & & & & \\
\hline & No & 6 & 8 & & & & \\
\hline \multirow[t]{3}{*}{8} & Tobacco & & & 0.20 & 3.84 & 1 & Not Significant \\
\hline & Yes & 5 & 7 & & & & \\
\hline & No & 9 & 9 & & & & \\
\hline \multirow[t]{3}{*}{9} & Alcohol & & & 0.20 & 3.84 & 1 & Not Significant \\
\hline & Yes & 5 & 7 & & & & \\
\hline & No & 9 & 9 & & & & \\
\hline \multirow[t]{4}{*}{10} & Diet & & & 1.03 & 5.99 & 2 & Not Significant \\
\hline & Vegetarian & 6 & 5 & & & & \\
\hline & Non-vegetarian & 7 & 8 & & & & \\
\hline & Eggetarian & 1 & 3 & & & & \\
\hline \multirow[t]{5}{*}{11} & Duration of illness & & & 1.72 & 7.81 & 3 & Not Significant \\
\hline & Less than 3 months & 2 & 3 & & & & \\
\hline & 3 month-1 year & 4 & 5 & & & & \\
\hline & $1-3$ year & 2 & 5 & & & & \\
\hline & More than 3 years & 6 & 3 & & & & \\
\hline \multirow[t]{5}{*}{12} & Regular follow up & & & 2.08 & 7.81 & 3 & Not Significant \\
\hline & Rarely & 3 & 2 & & & & \\
\hline & Unscheduled & 6 & 5 & & & & \\
\hline & In emergency & 4 & 5 & & & & \\
\hline & Scheduled & 1 & 4 & & & & \\
\hline
\end{tabular}

This shows that there is no significant association between the post-test adherence to treatment scores of heart failure patients in the experimental group and selected variables

\section{Mean percentage distribution of acceptability of mobile app.}

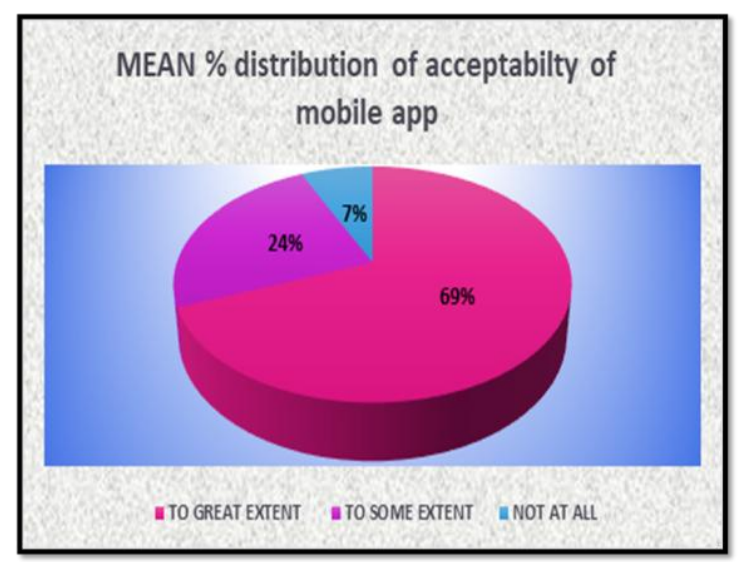

Figure: 1 - Pie diagram showing mean\% of acceptability and utility response on the structured opinionnaire.

\section{DISCUSSION}

- Major findings of the study were, the maximum number of patients were male $(63 \%),(50 \%)$ in the age group [50-60 yrs.] of having the sedentary life style (52\%), the education status $(47 \%)$ was $10-12^{\text {th }}$ pass, $(67 \%)$ were having average BMI and most of the heart failure patients were $(58 \%)$ non-vegetarian.

- The present study showed that the mobile app: Samrudheart was found to be an effective strategy in improving the knowledge, practice, and adherence to treatment of heart failure patients.

- The present study showed that the mean post-test knowledge score (21.6) of the patient get increase after the administration of mobile app. Similar findings were revealed by the study ${ }^{(11)}$ which showed that the patients have deficit knowledge regarding self- 
Poonam et.al. A study to develop and evaluate the effectiveness of a mobile app: samrudheart on self-care management of a patient with heart failure in terms of knowledge, practice, and adherence to treatment among heart failure patients in Safdarjung hospital, New Delhi.

care management of heart failure but after the discharge teaching it increases.

- The present study showed that the mean post-test practice score (21.43) of the patient get increase after the administration of mobile app. The similar findings were revealed by the study ${ }^{(12)}$ which showed that the patients have deficit practice regarding self-care management of heart failure but after the discharge teaching, it increases.

- The present study showed that the mean post-test adherence to treatment scores (22.9) of the patient get increase after the administration of the mobile app. The study ${ }^{(13)}$ done in India shows that the people have inadequate adherence to treatment regarding self-care management of heart failure and there should gave regular follow-up and adherence to treatment to improve the self-care management of heart failure and decrease the comorbidity.

- The findings of this study confirm with the study ${ }^{(14)}$ which showed that the use of the mobile app was found to be an effective strategy in increasing the knowledge, practice, and adherence to treatment of the heart failure patients regarding self-care management.

- The findings of this study confirm with the study ${ }^{(15)}$ which showed that the use of reminder call or telemonitoring was found to be an effective strategy in increasing the knowledge, practice, and adherence to treatment of heart failure patients regarding self-care management.

- There was a significant positive correlation between knowledge and practice scores (0.99), practice and adherence to treatment scores (0.98) and adherence to treatment and knowledge scores (0.98) of heart failure patients in the experimental group.

- There was no significant association between the post-test knowledge scores of heart failure patient in the experimental group and selected variables.
- There was no significant association between the post-test practice scores of heart failure patients in the experimental group and selected variables except for the regular follow-up.

- There was no significant association between the post-test adherence to treatment scores of heart failure a patient in the experimental group and selected variables. This shows that the knowledge, adherence to treatment is independent on its own, and not influenced by the selected variables except the practice scores are influenced by the regular follow-up.

- The acceptability and utility score of the mobile app: Samrudheart was close to the maximum scores. This indicates good acceptability and usability of the guideline by the heart failure patients.

\section{Limitations of the Study}

1) The study is confined to a small number of patients, i.e. 30 in the experimental and 30 in the control group which limits the generalization of findings only to the study sample.

2) The study was confined to a selected hospital i.e. cardiology OPD of Safdarjung hospital of Delhi because of the limited time framework for data collection, limiting the generalization of the findings only to the study sample.

3) The tool is valid and applicable only to literate and android phone user population.

4) Information given in the mobile app was only in Hindi language.

\section{CONCLUSION}

- The presented study identified that there was deficient knowledge, practice and adherence to treatment in heart failure patients.

- Education was necessary for improving the knowledge, practice, and adherence to treatment of the heart failure patients on self-care management of heart failure. 
Poonam et.al. A study to develop and evaluate the effectiveness of a mobile app: samrudheart on self-care management of a patient with heart failure in terms of knowledge, practice, and adherence to treatment among heart failure patients in Safdarjung hospital, New Delhi.

- The mobile app was effective to increase the knowledge of the patient on self-care management of heart failure.

- A mobile app was effective to increase the practice of the patient on self-care management of heart failure.

- A mobile app was effective to increase the adherence to treatment of the patient on self-care management of heart failure.

\section{IMPLICATIONS}

NURSING PRACTICE- This study shows the strong need to prepare self-instructional mobile app for the heart failure patient on self-care management of the patient with heart failure in promoting and reinforcing positive health behaviours.

NURSING EDUCATION- this study shows great attention towards the skill attainment in telemedicine, telehealth, compliance to treatment by regular monitoring by reminders and phone calls, providing the health education with the help of the mobile app and phone calls at the basic level of education in nursing.

\section{NURSING ADMINISTRATION- The} nursing administration department should provide an opportunity to the clinical nurse to adopt a program like a mobile app on self-instructional module for early detection and management of complication of heart failure to improve the quality of care of patients and to decrease the unnecessary burden to the hospital on unscheduled hospitalization. The nurse the administration should give suggestions to the hospital administrators on more and more adoption of these types of mobile apps for close monitoring of patient's condition like early detection of complication, self-care management of heart failure, regular followup, adherence to treatment closely, preventions of defaulters, and decreasing the unscheduled hospital admission.

NURSING RESEARCH- There is a need to promote a research-based practice and the use of evaluation methods to the major outcome and document the quality and costeffective care as for nursing moves towards an independent professional practice mode. Emphasis should also be laid on the publication of findings of research in the journals to disseminate the research-based evidence for nurse practitioners. It also can be presented at various nursing forums so that a greater number of nurses become aware of the importance of the use of mobile apps in various disease conditions.

\section{Acknowledgement: None}

\section{Conflict of Interest: None}

\section{Source of Funding: None}

\section{REFERENCES}

1. Brunner and Suddarth's. Textbook medical and surgical nursing,12th edition.US: Lippincott Williams \& Wilkins; 2010. 346347.

2. Mishra.S, Mohan JC, Nair T. Management protocols for chronic heart failure in India Indian Heart Journal. Volume 70, 2018; Pages 105-127 available on. https://doi.org/10.1016/j.ihj.2017.11.015

3. De Sousa MM, Almeida TD, Gouveia BD, de Carvalho MF, de Brito FM, dos Santos Oliveira SH. Relationship between self-care and social and clinical conditions of patients with heart failure. Journal of the Nursing Network of the Northeast, 2018; 19. available on www.revistarene.ufc.br

4. Athilingam $P$, Jenkins $B$. doi: 10.2196/10057 Mobile Phone Apps to Support Heart Failure Self-Care Management: Integrative Review JMIR Cardio. 2018 Jan-Jun; 2(1): e10057.

5. The times of India, promoted every heart counts, Jan 3, 2017.

6. Outlook the news scroll, 29 September 2019 last updated at 8:16 pm | Source: ians

7. Times of India 2019 Feb 20 [online]. Available from: https://times of India.Indiatimes.com/topic/heart-attacks

8. Mlynarska A, Golba K S, Mlynarski R, doi: 10.2147/CIA.S178393Capability for selfcare of patients with heart failure. 2018; 13 : 1919-192

9. Darrell M. West, Improving Health Care through Mobile Medical Devices and Sensors, October 22, 2013. 
Poonam et.al. A study to develop and evaluate the effectiveness of a mobile app: samrudheart on self-care management of a patient with heart failure in terms of knowledge, practice, and adherence to treatment among heart failure patients in Safdarjung hospital, New Delhi.

10. Vemula RK. The Role of mHealth in India: Understanding the Future Ramifications for Community Empowerment. In Health Communication in the Changing Media Landscape 2016. Palgrave Macmillan, Cham; (pp. 97-112)

11. Liou HL, Chen HI, Hsu SC, Lee SC, Chang $\mathrm{CJ}, \mathrm{Wu} \mathrm{MJ}$. The effects of a self-care program on patients with heart failure. Journal of the Chinese Medical Association. 2015 Nov 1;78(11):648-56. Available from DOI: $10.1016 / \mathrm{j} . j \mathrm{cma} .2015 .06 .004$

12. Mosleh SM, Darawad M. Patients' adherence to healthy behavior in coronary heart disease: risk factor management among Jordanian patients. Journal of Cardiovascular Nursing. 2015 Nov 1;30(6):471-8.

13. Harikrishnan S, Sanjay G, Agarwal A, Kumar NP, Kumar KK, Bahuleyan CG, Vijayaraghavan G, Viswanathan $\mathrm{S}$, Sreedharan M, Biju R, Rajalekshmi N. Oneyear mortality outcomes and hospital readmissions of patients admitted with acute heart failure: Data from the Trivandrum Heart Failure Registry in Kerala, India.
American heart journal. 2017 Jul 1;189:1939. Available from https://europepmc.org > article > pmc > pmc7263011

14. Available from https://www.livemint.com.

15. Inglis SC, Clark RA, McAlister FA, Stewart $\mathrm{S}$, Cleland JG. Which components of heart failure programs are effective? A metaanalysis of the outcomes of structured telephone support or telemonitoring as the primary component of heart failure management. European Journal of Heart Failure. 2011;13:1028-40.available from: https://pubmed.ncbi.nlm.nih.gov

How to cite this article: Poonam, Dey M, Mathur RG et.al. A study to develop and evaluate the effectiveness of a mobile app: Samrudheart on self-care management of a patient with heart failure in terms of knowledge, practice, and adherence to treatment among heart failure patients in Safdarjung hospital, New Delhi. Int J Health Sci Res. 2021; 11(6): 234-248. DOI: https://doi.org/10.52403/ijhsr.20210637 